\title{
Factors Contributing to Parasuicide among Patients Aged 18 - 35 Admitted at a National Psychiatric Hospital, Zimbabwe
}

\author{
Dembetembe Maravanyika Mutsapata, Virgininia Dube-Mawerewere \\ University of Zimbabwe \\ Email:dmutsapata@gmail.com,virgydube@gmail.com
}

How to cite this paper: Mutsapata, D.M. and Dube-Mawerewere, V. (2017) Factors Contributing to Parasuicide among Patients Aged 18 - 35 Admitted at a National Psychiatric Hospital, Zimbabwe. Open Journal of Nursing, 7, 893-904.

https://doi.org/10.4236/ojn.2017.78066

Received: July 5, 2017

Accepted: August 12, 2017

Published: August 15, 2017

Copyright (c) 2017 by authors and Scientific Research Publishing Inc. This work is licensed under the Creative Commons Attribution International License (CC BY 4.0).

http://creativecommons.org/licenses/by/4.0/

\begin{abstract}
The purpose of the study was to determine factors contributing to parasuicide among patients aged 18 - 35 admitted at the national referral psychiatric hospital in Zimbabwe. A purposive sample of 32 respondents was selected for the study. Data were collected using a structured interview guide. All (100\%) of parasuicide participants had mental illness and were experiencing severe financial difficulties. Early identification and response to these problems would have prevented morbidity associated with parasuicide.
\end{abstract}

\section{Keywords}

Parasuicide, Factors, National Referral Psychiatric Hospital, Patients

\section{Introduction and Background}

According to World Health Organization, lack of parasuicide documentation leaves a large gap in our understanding of not only the number of parasuicide cases, but also the dimension of suicide. Available research indicates that parasuicide is the strongest predictor of suicide. Data available are mostly in North, East and West Africa and there is scanty information available on parasuicide for Southern African countries [1]. Empirical evidence demonstrates that 7 out of 53 African countries have available parasuicide data and this is less than $20 \%$ [2]. Although there seems to be underreporting reporting in Africa, there is enough evidence that parasuicide is a disturbing universal behaviour.

Zimbabwe is categorised as one of the countries with highest suicide rates in the world. The country is ranked 20th in the world with an annual age adjusted rate of 18.35 per 100,000 deaths [3]. Available data show an increasing trend of 
suicidal deaths in the country from 7.9 per 100,000 in the 1990s to the current 18.35 per 100,000 populations (WHO 2016). A $320 \%$ increase in organophosphate poisonings has been reported in urban Zimbabwe from 1995 to 2000 [4]. According to hospital statistics at the national referral psychiatric hospital in Zimbabwe, there were thirty-four parasuicide admissions of the 18 - 35 years age group in the period between April 2014 and March 2015. Beyond that, Zimbabwe has very little empirical evidence about the determinants or factors contributing to parasuicide especially among patients that are referred and admitted at the national referral psychiatric hospital in Zimbabwe. Cultural factors or the fact that the parasuicide patients would not have actually died may be an important lever in under reporting. In the process, the magnitude of the problem is undermined. The study therefore sought to describe factors contributing to parasuicide and identify methods used for parasuicide among patients aged 18 - 35 at a national referral psychiatric hospital in Zimbabwe.

\section{Methodology}

The study was conducted at the only national referral psychiatric hospital in Zimbabwe. A quantitative descriptive survey was used. The sample (32) size was determined by respondents who were actually present at the time of the study. Respondents were recruited between 1 July 2016 and 31 August 2016 over a 2 month period. Purposive sampling of all respondents/patients admitted with a history of parasuicide at the time of the study was done. Parasuicide was operationalized as deliberate self-harming or self-poisoning, irrespective of the purpose but did not result in death [5]. Contributory factors were operationalized as any behaviour, omission or deficiency that if corrected, would have eliminated or prevented parasuicide. This study utilized structured interviews to describe factors contributing to parasuicide.

Inclusion criteria:

- Patients who were admitted and available at the time of data collection.

- Patients who had fully recovered from adverse effects of parasuicide and were broad conscious.

- Patients had to be aged between 18 - 35 years.

- Patients who were willing to discuss the circumstances surrounding the parasuicide.

Data were analysed using Statistical Package for Social Sciences (SPSS) version 16.0. Descriptive statistics characterised the respondents.

\section{Ethics}

Permission to conduct the study at the national referral psychiatric hospital was sought from the Institutional Review Board proxy in the person of the Chief Executive Officer of the hospital. Final authority to conduct the study was obtained from the Medical Research Council of Zimbabwe. Respondents/patients involved in the study also availed individual informed written consent. 


\section{Results of the Study}

The following are the demographic variables of respondents who had parasuicide. Demographic variables will be followed by risk factors for parasuicide among respondents.

\subsection{Age}

Data from this study showed that the greater number of respondents $12(37.7 \%)$ were between the ages 31 - 35 years followed by 10 (31\%) who were between the ages of 21 - 25 years. This is in line with a study that cited that highest rates of parasuicide in Europe were among adults 24 - 34 years [6]. This implies that parasuicide increases with age from late teenager hood to middle adulthood as there is a myriad of issues including social responsibilities, relationships, employment and general societal expectations. In the study context, it is also important to note that the age range could have also been influenced by the fact that the study site did not cater for patients/respondents below the age of 18 years.

\subsection{Marital Status}

Single persons in this study $65 \%$ were the major group for parasuicide. This notion is supported by a study that discovered that there is a consistently lower frequency of parasuicide among married persons with dependent children [7]. This could be due to an increased sense of responsibility as well as possible selection bias associated with relatively healthy and successful adaptation. Single persons could also be affected by stressful life events against which they may be lacking exposure and experience to handle leading them to parasuicide as an escape.

\subsection{Religion}

Ninety-two percent (92\%) of the respondents in the study were Christians. Most religions oppose parasuicide and rates vary considerably among religions and between areas with a predominant religion [8]. Parasuicide rates are lower in countries with strong sanctions against parasuicide for example Islamic states. A further explanation has been availed that prayer is a protective factor against negative life events and it promotes positive wellbeing and health [3]. The common religion in Zimbabwe is Christianity. It is generally believed that religious members provide non-judgemental support through prayers, emotional support, love, caring and follow up to persons who have attempted parasuicide and this is purported to reduce parasuicide among Christians. Study results therefore imply that being a Christian does not protect an individual against parasuicide. This means that safeguarding one's own life is an individual responsibility.

\subsection{Family Size}

More than half the number of respondents, $58 \%$, originated from families with 
three to five members. Study results are in line with a Bangladesh study that showed that more than half of participants had between 4 to 6 members in the family [9]. This type of family in the study context is perceived as a small family. This may imply that small families could be lacking the capacity to function as an adequate support system exposing its members to parasuicide.

\subsection{Educational Level}

The study findings show that the majority $54 \%$ of respondents had secondary school as their highest level of education. This is considered as lower to average educational level in the study context. It has been positioned that both high and low levels of education are associated with suicide at both individual level and aggregate level [10]. Respondents had mental health problems which in itself is associated with both lower intelligence and lower educational attainment. This could have become a catalyst to parasuicide resulting from poor problem solving abilities under inherent difficult circumstances.

\subsection{Employment Status}

Fifty-eight percent $58 \%$ of respondents were unemployed while the rest were self-employed within an unstable economic environment. Employment has been identified as a mitigatory factor against suicide [11]. Respondents in the study were unemployed and already vulnerable to parasuicide because of the existing mental ill health. It is then conceivable that being unemployed made it difficult for respondents to plan for their future when there were limited sources of income leading them to parasuicide.

\subsection{Living Circumstances}

Forty six percent (46\%) of respondents were staying with parents while $42 \%$ were staying with relatives. The remainder of respondents were of no fixed abode. Related studies have consistently correlated high risk of parasuicide with people living alone [12]. In a South African City study, an evidence based position was made that area-based compositional and socio-physical characteristics have a bearing on sociality [13]. In the study setting, respondents lived in low resource settings. Under such circumstances, it is possible that most families could have been dysfunctional due to unstable living conditions with an added burden of caring for a mentally ill person (the respondent). This could lead the affected person/patient to mal-adapt and desire to kill self.

\subsection{Geographic Location}

More than half $(69 \%)$ of the respondents in this study were staying in urban areas. Previous work found that population density and distance from both human and material resources influence suicide rates because of inherent economic disadvantage [14] [15]. Urban settings in the study context were perceived to be of high population density and of poor accessibility to social, economic and 
health resources. This could have translated to high demands of urban life and poor support systems fuelling incidences of parasuicide in the context of the study.

\subsection{Risk Factors to Parasuicide for Respondents Admitted at the National Referral Psychiatric Hospital}

The following are results showing those factors that made the respondents vulnerable to parasuicide.

\subsection{Parasuicide Ideation in the Past 12 Months}

Results showed that $46 \%$ of respondents had never thought of attempting suicide before. Fifty four percent (54\%) were spread along not being sure or having actual suicidal ideation. There is means that there could be a link between suicidal thoughts and parasuicide [16]. The authors further explain that mental disorders in which suicide ideators have hopelessness are robust predictors of parasuicide. It is a possibility in the study context that the mental illness itself could have precipitated and triggered the parasuicide both as a disease process and as a sign of the respondent's despair and hopelessness owing to their prevailing circumstances and just having to live with negativity associated with mental illness.

\subsection{Circumstances Surrounding the Parasuicide}

More than half of respondents (58\%) in this study verbalised that divorce and bereavement triggered the parasuicide. Results of a multivariate logistic regression analysis showed that after controlling for psychiatric, social and economic predictors of suicide, the odds were high for a most recent divorce than for distal divorce [17]. Research has proven that the risk of parasuicide during bereavement is associated with survivors whose culture embraces "death taboo" [18]. These survivors perceive high levels of stigma which they escape through suicide. This may imply that inability to cope with losses may result in hopelessness, helplessness and giving up. Divorce and bereavement bring emotional pain, shame, loss, frustration and feeling of hopeless and failure in life to maintain a relationship to an individual and their families. In the study context, respondents were individuals who already had psychiatric conditions. While they were still struggling to adapt to that predicament, a loved one either died or their spouse decided they could not live with them. This then overwhelmed the respondent patients, pushing them towards ending it all through a suicide attempt.

\subsection{Issues of Hope}

Half of the respondents $50 \%$ verbalised that they had lost hope while the other $50 \%$ asserted that there was life after their prevailing circumstances. Loss of hope, depression and social factors put people at high risk of parasuicide [4]. In other words, hope may be a protective factor against suicidal individuals. Respondents in the study were exposed to a number of stressors simultaneously in 
the backdrop of a fragile support system and this led them to parasuicide. The context or environment in which the respondents were did not offer mediation against parasuicide.

\subsection{Beyond the Present Parasuicide}

Sixty eight percent (68\%) verbalised that they were not sure what was to happen next after the present parasuicide. The World Health Organization [19] states that parasuicide may be a genuine attempt by the person to kill themselves or it may be self-injurious behaviour without the intension to kill oneself but to draw attention to personal problems. This means that there was a possibility that respondents could repeat the parasuicide. It means they were still not convinced that they could continue living in the face of their circumstances. Or it means that whatever the attempted suicide was trying to draw attention to was not addressed either by the family or the health delivery system.

\subsection{Communicating Parasuicide Intentions}

In this study, $31 \%$ of respondents verbalised that they kept it as a secret that they intended to kill themselves. In a study conducted on suicide attempters between the ages of 15 - 24 years, it was found that communication of distress that led to parasuicide was hampered by fear of self-exposure, negative repercussions and being thought of as being mentally unstable [20]. This translates to the notion that respondents wanted to die in silence as a way of communicating hurt, anger and frustration to loved ones. In the study context which is African and Zimbabwean, the socialization processes generally does not foster expressing of such emotions as they are perceived as a sign of weakness, hence the secrecy. It is therefore possible that the respondents had strong inhibitions against openly expressing anger and frustration that develop from conflictual and stressful situations.

\subsection{Time of the Day when Parasuicide Occurred}

The majority of respondents in this study attempted suicide in the following times of the day; (27\%) in the morning, $(27 \%)$ in the afternoon and $(27 \%)$ in the evening and the remainder could not remember. It has been found that there is marked diurnal variation with regards to parasuicide, with an evening peak for nonviolent episodes [21]. In the study context, the time of the day did not make a difference to parasuicide as evidenced by almost equal distribution of times of day for parasuicide. The psychosocial explanation for this pattern of deliberate self-harm depended on the circumstances of the respondent preceding the parasuicide.

\subsection{Strength of Relationship with Immediate Family Members}

The study revealed that a cumulative $81 \%$ of respondents had conflicts with either spouses, immediate family members or relatives. Poor family relationships 
and unstable family dynamics are robust parasuicide predictors [22]. In the study context, families are inherently commune, family members' functionality from a psychological, social and economic spectrum is collective. This means that any form of relational dysfunction or dissonance within a family becomes an important lever in the occurrence of parasuicide because it symbolises rejection.

\subsection{Dependents of Respondents}

The research found that only $35 \%$ of respondents had no dependents. The rest (65\%) had children who were being taken care of either by relatives or the partner who had divorced them. Research has suggested that social roles like that of taking care of the family are bound to employment or economic conditions [23]. Respondents in this study were not capable of providing for their families. In the study context, respondents were generally expected to have families of their own. Actually not having dependents and being taken care of by someone else is perceived to be the ultimate sign of failure. On the other hand, having one's own children being brought up by relatives or the spouse that left is a form of loss that can put a mental patient (respondent) at risk of committing suicide.

\subsection{Specific Preparations to Attempt Suicide}

More than half the number of participants in this study $58 \%$ did not plan at all to attempt parasuicide. In a related study, findings showed that the plan factor was related to key suicide indices that revolved around previous suicide [24]. In the study context, results may indicate that parasuicide is a desperate move and an impulsive act where problem solving skills of an individual would have failed and they decide to back off from the traumatic experience through death.

\subsection{Previous Parasuicide}

A significant number of respondents in this study $54 \%$ verbalised that they had attempted suicide in the past. A logistic regression model identified previous history of suicide and mental illness as significant predictors for repeat parasuicide [25]. The same authors also highlighted that the risk of repeat parasuicide tends to increase as the number of risk factors increase. In the study context, the respondents were exposed to a myriad of risk factors that included mental ill health and lack of family support. This means that parasuicide should be taken seriously as there are high chances of repeating the act which may eventually result in loss of life.

\subsection{Self-Concept of Parasuicidee}

The majority of respondents in this study (73\%) verbalised that they chronically experienced low self-esteem and verbalised feeling used and abused. A comparable study correlated the profile of a parasuicidal patient with low self-concept and problem solving difficulties [26]. Respondents may have developed a nega- 
tive self-concept because of the existing mental illness that has severe stigma attached to it in the study context. The respondents' perception of being used and abused also fed into the negative self-concept leading to parasuicide.

\subsection{Financial Status of Parasuicidee}

The majority of participants in this study were financially dependent. In a corresponding South African study most participants indicated that financial difficulties and lack of support were the main reasons for parasuicide [25]. There is an association between low socioeconomic position and parasuicide whereby there is even a threefold increased risk in lower socioeconomic position groups [2]. In the study context, the respondents were from a very low income country which means that they were economically disadvantaged. This means that lack of economic independence then became an entry point of problems including abuse, frustration that culminated in parasuicide.

\subsection{Parenting History of Parasuicidee}

More than half of respondents in this study (62\%) who came in with parasuicide grew up with both parents during their childhood. People who attempt suicide come from abusive and traumatic environments [27]. A separate study demonstrated that there was a childhood pattern of exposure to irresponsible and overprotective parenting among adult parasuicidal patients [28]. In the study context, it is possible that respondents came from dysfunctional families where there was no family cohesion characterised by abuse of the respondents. On the other hand this could have resulted from overprotection of children by parents during childhood leading to failure to face the future and cope with life challenges as adults hence the occurrence of parasuicide.

\subsection{Individual Experiences that Might Have Specifically Contributed to Parasuicide}

The bulk of respondents in this study (100\%) suffered from mental illness, (73\%) experienced severe financial problems, (73\%) verbalised failure to cope with life. All these issues are consistent with literature. There was an association between borderline personality disorder (that presents with instability and impulsivity) and parasuicide [29]. An equivalent study found that experiencing a limited fiscal space is a significant predictor of psychological distress [30] [31]. In a study conducted to determine if problem solving ability was related to parasuicide, it was found that those that tended to repeat parasuicide had significantly higher scores on the passive reaction dimension [32]. The issues of mental illness, economic disadvantage and failure to cope with life in literature discussed above also applied to respondents under this study.

\subsection{Materials Used to Attempt Suicide}

More than half of respondents in this study $(60 \%)$ took a myriad of tablets that 
they were able to access. In a study conducted in Zimbabwe it was found that common methods used for parasuicide included hanging, drowning and use of pesticides [33] [34]. The study context is distinctively similar but these particular respondents participating in this study were already on medication for mental illness and other conditions like HIV/AIDS. This made drugs readily available to use for attempting suicide.

\section{Conclusion}

Suicidal behaviour is a growing public health problem that has significant socioeconomic and health effects on individuals, families and communities in Zimbabwe. The young male single dependent adults with a lower level of education were the most vulnerable group to parasuicide. Dysfunctional family dynamics, inability to cope, severe financial difficulties and previous history of parasuicide were significant predictors of the present parasuicide. The common methods used in this study were, taking medication tablets overdose and hanging. The hallmark of parasuicide in the study was underlined by the diagnosis of a psychiatric disorder for all the respondents.

\section{Implications of the Study}

It is imperative for policy makers, practitioners to refocus on the following issues:

- Advocating for parasuicide registers in health centres and hospitals, as there are limited documented parasuicide registers on the ground. This may suggest that there is under reporting and misdiagnosis and inappropriate treatment to clients as they visit health centres.

- Acknowledging that psychiatric patients have an inherent predisposition to parasuicide and taking that into consideration at assessment, intervention and discharge.

- Utilising research results of this study to train nurses, doctors, social workers and psychologists to manage patients with this problem better with deeper understanding of the health problem and putting more emphasis on addressing risk factors and recommending appropriate interventions.

- Taking parasuicide clients seriously during the time when they verbalise or directly or indirectly communicate suicidal ideation.

- Limiting the number of medications dispensed to psychiatric patients to levels that do not allow overstocking of drugs to prevent availability of such medications being used as a weapon for parasuicide.

\section{Limitations}

This study was a hospital based study based on a small sample size. The study results cannot be generalizable beyond the context of the study. The research would need to be replicated using a wider sample and more robust quantitative and qualitative methods to have a broader perspective of both the magnitude of 
the problem towards developing a context specific way forward for the parasuicide problem in Zimbabwe.

\section{References}

[1] Knipe, D.W., Carroll, R., Thomas, K.L., Pease, A., Gunnell, D. and Metcalfe, C. (2015) Association of Socio-Economic Position and Suicide/Attempted Suicide in Low and Middle Income Countries in South and South-East Asia-A Systematic Review. BMC Public Health, 15, 1055. https://doi.org/10.1186/s12889-015-2301-5

[2] Mars, B., Burrows, S., Hjelmeland, H. and Gunnell, D. (2014) Suicidal Behaviour across the African Continent: A Review of the Literature. BMC Public Health, 14, 606. https://doi.org/10.1186/1471-2458-14-606

[3] World Health Organization (WHO) (2014) Preventing Suicide. A Resource for Non-Fatal Suicidal Behaviour Case Registration. The World Health Organization, Geneva.

[4] Dong, X. and Simon, M.A. (2001) The Epidemiology of Organophosphate Poisoning in Urban Zimbabwe from 1995 to 2000. International Journal of Occupational and Environmental Health, 7, 4. https://doi.org/10.1179/oeh.2001.7.4.333

[5] Wachholtz, A. and Sambamoorthi, C. (2011) National Trends in Prayer Use as a Coping Mechanism for Health Concerns: Changes from 2002-2007. American Psychology Association.

[6] Davidson, C.L., Wingate, L.R., Slish, M.L. and Rasmussen, K.A. (2010) The Great Black Hope: Hope and Its Relation to Suicide Risk among African Americans. Suicide and Life-Threatening Behavior, 40, 170-180.

https://doi.org/10.1521/suli.2010.40.2.170

[7] National Institute for Health and Clinical Excellence (NICE) (2004) Self-Harm: The Short-Term Physical and Psychological Management and Secondary Prevention of Self-Harm in Primary and Secondary Care. National Clinical Practice Guideline No. 16, London.

[8] Hawton, K., Saunders, K.E. and O'Connor, R.C. (2012) Self-Harm and Suicide in Adolescents. The Lancet, 379, 2373-2382.

[9] Tondo, L., Pompili, M., Forte, A. and Baldessarini, R.J. (2015) Suicide Attempts in Bipolar Disorders: Comprehensive Review of 101 Reports. Acta Psychiatrica Scandinavica, 133, 174-186. https://doi.org/10.1111/acps.12517

[10] Tondo, L. and Baldessarini, R.J. (2015) Suicide: Causes and Clinical Management. Medscape.

[11] Reza, A.S., Feroz, A.H.M., Nurulislam M.D., Rabbani, G., Shahalam, M.D., Rahman, M.M.R., Ahmed, H.U., Bhowmik, A.D., Khan, M.Z., Sarkar, M., Tariqulalam, M. and Uddin, M.M.J. (2013) Risk Factors of Suicide and Parasuicide in Rural Bangladesh. Journal of Medicine, 14, 123-129.

[12] Shah, A. and Bhandarkar, R. (2009) The Relationship between General Population Suicide Rates and Educational Attainment: A Cross-National Study. Suicide and Life-Threatening Behavior, 39, 463-470. https://doi.org/10.1521/suli.2009.39.5.463

[13] Corcoran, P. and Arensman, E. (2010) Suicide and Employment Status during Ireland's Celtic Tiger Economy. European Journal of Public Health, 21, 209-214.

[14] Hawton, K. and Heeringen, H. (2000) The International Handbook of Suicide and Attempted Suicide. John Willy and Sons Ltd., Manchester. https://doi.org/10.1002/9780470698976 
[15] Burrows, S. and Laflamme, L. (2005) Living Circumstances of Suicide Mortality in a South African City: An Ecological Study of Differences across Race Groups and Sexes. Suicide and Life-Threatening Behavior, 35, 592-603. https://doi.org/10.1521/suli.2005.35.5.592

[16] Stark, C., Hopkins, P., Gibbs, D., Belbin, A. and Hay, A. (2007) Population Density and Suicide in Scotland. Rural Remote Health, 7, 672.

[17] Mayumi Oka, M., Kubota, T., Tsubaki, H. and Yamauchi, K. (2015) Analysis of Impact of Geographic Characteristics on Suicide Rate and Visualization of Result with Geographic Information System. Psychiatry and Clinical Neurosciences, 69, 375-382. https://doi.org/10.1111/pcn.12254

[18] Klonsky, E.D., May, A.M. and Saffer, B.Y. (2016) Suicide, Suicide Attempts, and Suicidal Ideation. Annual Review of Clinical Psychology, 12, 307-330.

https://doi.org/10.1146/annurev-clinpsy-021815-093204

[19] Stack, S. and Scourfield, J. (2015) Recency of Divorce, Depression, and Suicide Risk. Journal of Family Issues, 36, 695-715. https://doi.org/10.1177/0192513X13494824

[20] Pitman, A., Rantell, K., Marston, L., Michael King, M. and Osborn, D. (2017) Perceived Stigma of Sudden Bereavement as a Risk Factor for Suicidal Thoughts and Suicide Attempt: Analysis of British Cross-Sectional Survey Data on 3387 Young Bereaved Adults. International Journal of Environmental Research, 14, 1-12.

[21] Wasserman, D., Thanh, H.T.T., Minh, D.P.T., Goldstein, M., Nordenskiold, A. and Wasserman, C. (2010) Suicidal Process, Suicidal Communication and Psychosocial Situation of Young Suicide Attempters in a Rural Vietnamese Community. World Psychiatry, 7, 47-53. https://doi.org/10.1002/j.2051-5545.2008.tb00152.x

[22] Blenkiron, P. (2003) The Timing of Deliberate Self-Harm Behaviour. Irish Journal of Psychological Medicine, 20, 126-131. https://doi.org/10.1017/S079096670000793X

[23] Zhai, H., Bai, B., Chen, L., Han, D., Wang, L., Qiao, Z., Qiu, X., Yang, X. and Yang, Y. (2015) Correlation between Family Environment and Suicidal Ideation in University Students in China. International Journal of Environmental Research and Public Health, 12, 1412-1424. https://doi.org/10.3390/ijerph120201412

[24] Economou, M., Madianos, M., Peppou, L.E., Theleritis, C, Patelakis, A. and Stefanis, C. (2013) Suicidal Ideation and Reported Suicide Attempts in Greece during the Economic Crisis. World Psychiatry, 12, 53-59. https://doi.org/10.1002/wps.20016

[25] Joiner, T.E., Steer, R.A., Brown, G., Beck, A.T., Pettit, J.W. and Rudd, M.A. (2003) Worst-Point Suicidal Plans: A Dimension of Suicidality Predictive of Past Suicide Attempts and Eventual Death by Suicide. Behaviour Research and Therapy, 41, 1469-1480.

[26] Obida, M. and Govender, I. (2013) Reasons for Parasuicide among Patients Admitted to Tshilidzini Hospital, Limpopo Province: A Qualitative Study. South African Journal of Psychiatry, 19, 222-225. https://doi.org/10.7196/sajp.452

[27] Santos, J.C., Saraiva, C.B. and De Sousa, L. (2009) The Role of Expressed Emotion, Self-Concept, Coping, and Depression in Parasuicidal Behavior: A Follow-up Study. Archives of Suicide Research, 13, 358-367. https://doi.org/10.1080/13811110903266590

[28] Taylor, C.J., Kent, G.G. and Huws, R.W. (1994) A Comparison of the Backgrounds of First Time and Repeated Overdose Patients. Journal of Accident and Emergency Medicine, 11, 238-242. https://doi.org/10.1136/emj.11.4.238

[29] Silove, D., George, G. and Bhavani-Sankaram, V. (1997) Parasuicide: Interaction between Inadequate Parenting and Recent Interpersonal Stress. Australian \& New 
Zealand Journal of Psychiatry, 21, 221-228.

https://doi.org/10.3109/00048678709160915

[30] Goethem, A., Mulders, D., de Jong, J., Arntz, A. and Egger, J. (2015) Self-Injurious Behaviour and Suicidal Ideation during Dialectical Behaviour Therapy (DBT) of Patients with Borderline Personality Disorder. Clinical Neuropsychiatry, 12, 37-45.

[31] Gorgievski, M.J., Bakker, A.B., Schaufeli, W.B., van der Veen, H.B. and Giesen, C.W.M. (2010) Financial Problems and Psychological Distress: Investigating Reciprocal Effects among Business Owners. Journal of Occupational and Organizational Psychology, 83, 513-530. https://doi.org/10.1348/096317909X434032

[32] Ramdurg, S., Goyal, S., Goyal, P., Sagar, R. and Sharan, P. (2011) Socio-Demographic Profile, Clinical Factors and Mode of Attempt in Suicide Attempters in Consultation Liaison Psychiatry in a Tertiary Care Centre. Industrial Psychiatry Journal, 20, 11-16. https://doi.org/10.4103/0972-6748.98408

[33] McAuliffe, C., Keeley, H.S. and Corcoran, P. (2002) Problem Solving and Repetition of Parasuicide. Behavioural and Cognitive Psychotherapy, 30, 385-397. https://doi.org/10.1017/S1352465802004010

[34] Munikwa, J., Mutopa, S. and Maphosa, C. (2012) The Nature and Causes of Parasuicide Cases Handled by Traditional Leaders in Hurungwe District in Zimbabwe. Journal of Human Ecology, 37, 93-102.

\section{Scientific Research Publishing}

Submit or recommend next manuscript to SCIRP and we will provide best service for you:

Accepting pre-submission inquiries through Email, Facebook, LinkedIn, Twitter, etc. A wide selection of journals (inclusive of 9 subjects, more than 200 journals) Providing 24-hour high-quality service User-friendly online submission system Fair and swift peer-review system Efficient typesetting and proofreading procedure

Display of the result of downloads and visits, as well as the number of cited articles Maximum dissemination of your research work

Submit your manuscript at: http://papersubmission.scirp.org/

Or contact ojn@scirp.org 